\title{
A Vida dos Elementos Químicos
}

J O SÉ J. G. MO UR A *

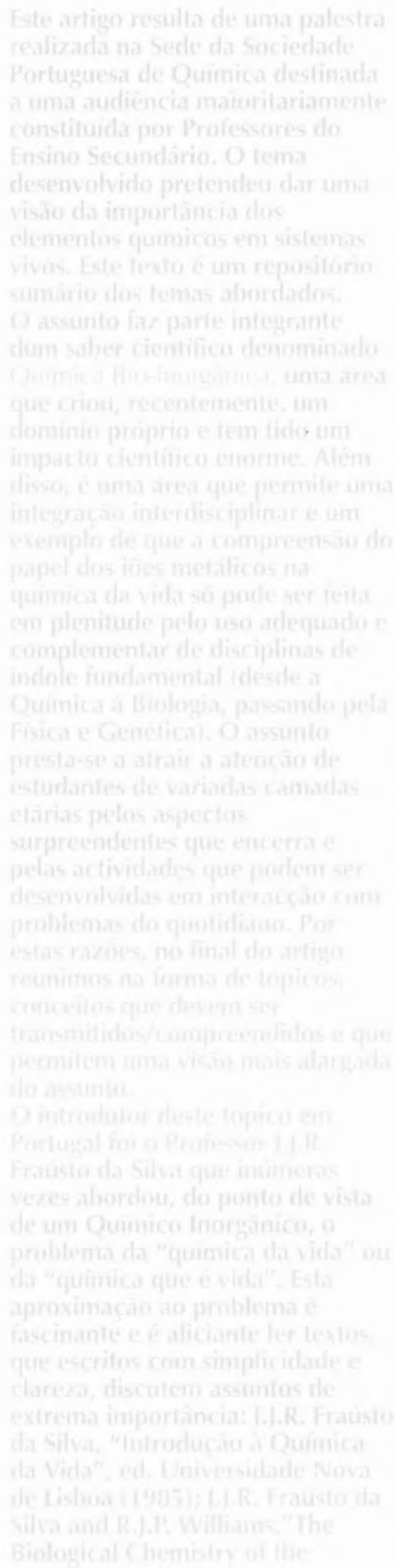

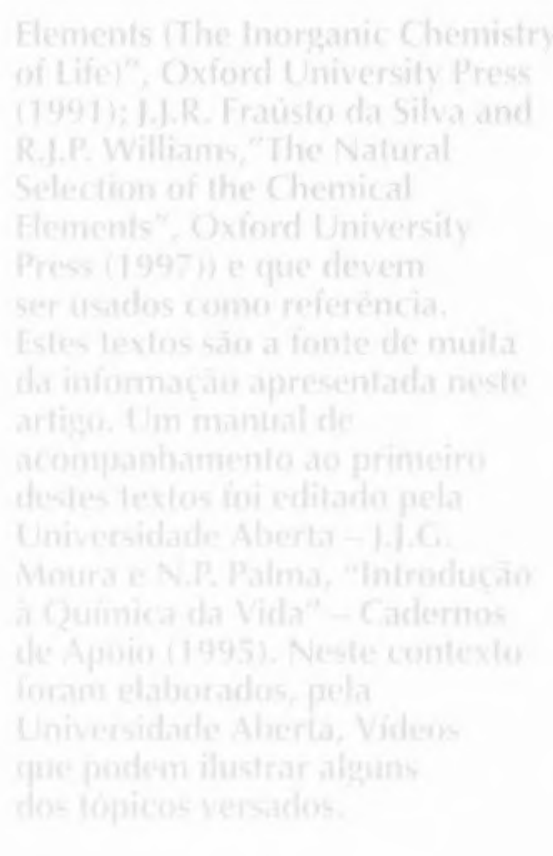

\section{A - INTRODUÇÃO}

A vida é o resultado de um longo processo evolutivo. Os elementos químicos preponderantes nas primeiras estrelas do Universo eram o HÉLIO e o HIDROGÉNIO, elementos quimicamente inertes. Após um longo processo de maturação dessas estrelas, foram-se formando elementos mais pesados, como CARBONO, AZOTO, OXIGÉNIO e todos os outros elementos da tabela periódica. Durante este processo algumas estrelas tornaram-se grandes e instáveis, explodindo. A sua desintegração deu origem às estrelas e sistemas planetários, tal como os conhecemos hoje, ricos em elementos pesados. No entanto, e apesar de ricas em elementos reactivos, as estrelas também não permitem qualquer tipo de química, pois o seu calor intenso decomporia qualquer possível composto químico nos seus constituintes. Por outro lado, no espaço e planetas frios, ou mesmo na nossa Lua, é possível encontrar alguma reactividade química, mas as baixas temperaturas tornam as reacções muito lentas, não sendo possível formar as moléculas complexas que caracterizam os seres vivos tal como nós os conhecemos. As condições particulares de um planeta como a Terra, com um ambiente moderado mas em constante actividade, terão reunido as condições necessárias à formação dos primeiros seres vivos. A atmosfera primitiva da Terra era rica em amoníaco, metano e vapor água, constantemente sujeita a radiações provenientes do exterior e às descargas eléctricas originadas nas frequentes tempestades atmosféricas. Estas condições teriam levado à formado das primeiras moléculas orgânicas, cada vez mais complexas, e que se concentrariam na fase aquosa de charcos e lagoas, onde se pensa terem surgido as primeiras formas organizadas com capacidade de auto-reprodução, que é sem dúvida, uma das propriedades mais características dos seres vivos.

A evolução das espécies deu origem à enorme diversidade e complexidade dos organismos vivos que hoje povoam a Terra. No entanto, e apesar dessa grande diversidade de formas de vida, pode dizer-se que todas elas partilham dos mesmos tipos de processos biológicos fundamentais. Para além disso, estes processos são controlados por um número limitado de grupos de macromoléculas, que são comuns a todos os seres vivos. As macromoléculas são em geral polímeros formados por unidades elementares que podem ou não repetir-se com uma certa regularidade. Os quatro grupos principais de macromoléculas encontradas nos seres vivos são: PROTEÍNAS, ÁCIDOS NUCLEICOS, POLISSACÁ-RIDOS e LÍPIDOS. Todas elas são constituídas por unidades simples, verdadeiros blocos construtores de um edifício complexo. Esta organização estrutural e funcional está na base da maioria dos organismos eucariotas, desde os unicelulares até aos organismos pluricelulares mais complexos, numa hierarquia de organização crescente.

\section{B - OS ELEMENTOS DA QUIMICA DA VIDA}

Os elementos constitutivos dos materiais biológicos

Os materiais biológicos são constituídos por determinados elementos seleccionados entre os que 
ocorrem naturalmente. A análise química de uma grande variedade de organismos, órgãos, células, tecidos, etc. permitiu verificar que apenas onze elementos são predominantes nos materiais biológicos (constituindo $99.9 \%$ do corpo humano, por exemplo) e que apenas quatro - carbono, hidrogénio, oxigénio e azoto - representam $99 \%$ daquele total. Os restantes sete elementos - sódio, magnésio, potássio, cálcio, fósforo, enxofre e cloro, correspondem a cerca de $0.7 \%$ do total dos elementos e um grupo de pelo menos dezasseis elementos (em geral metais de transição), considerados vestigiários, são essenciais à vida tal como a conhecemos. Em conclusão podemos dizer que a química biológica utiliza em abundância elementos metálicos e não metálicos leves (número atómico menor que 30).

\section{Os elementos mais abundantes}

o hidrogénio e o oxigénio, os elementos mais abundantes, aparecem em elevada percentagem em forma combinada (água) - cerca de $70 \%$ no corpo humano. A água é uma substância básica e condicionante em termos de $\mathrm{pH}$ e potencial de oxidação-redução (Ver Apêndice A).

A presença de carbono, o terceiro elemento mais abundante nos seres vivos, é surpreendente pelo facto de ser pouco abundante na crusta terrestre, em oposição ao silício. Verifica-se aqui portanto uma clara opção pelo utilização de carbono (ver Selecção dos Elementos Quími$\underline{\cos }$ ).

O quarto elemento mais abundante é o azoto, preponderante na atmosfera como um gás. Alguns organismos (bactérias e certas plantas) têm a capacidade de o fixar directamente. Os outros têm daquelas ou de fontes subsidiárias sob uma forma assimilável ou sob a forma de moléculas biológicas (i.e. amino-ácidos, proteínas, etc.) (ver Ciclos dos Elementos).

O enxofre e o fósforo são elementos importantes na constituição das principais moléculas biológicas: amino-ácidos, açúcares, ácidos gordos e nucleotídos intervenientes na constituição de macromoléculas (proteínas, polissacáridos, lípidos e ácidos nucleicos. O tecido ósseo é constituído por fosfato de cálcio.

\section{Os elementos menos abundantes}

Cálcio, sódio, potássio e magnésio são metais importantes na constituição dos seres vivos. Por razões de electroneutralidade, nos fluidos biológicos existem aniões tais como cloreto e fosfato/sulfato (derivados do fósforo e enxofre).

\section{Os elementos vestigiários}

Este grupo de elementos é constituído pelos oligo-elementos. Requeridos em muito baixo teor têm um papel único e muito importante nos processos vitais. Os metais de transição desempenham um papel fundamental. Em geral estão associados a processos catalíticos (por exemplo o ferro no transporte de oxigénio no sangue - hemoglobina, molibdénio (ou vanádio) e ferro na fixação de azoto atmosférico ou níquel e ferro na produção/consumo biológico de hidrogénio). A noção e efeito de carência ou de excesso destes componentes será discutida adiante.

O meio ambiente condicionador da química da vida

Uma das características da vida é a continua adaptação a mudanças de condições ambientais. Para isso foram desenvolvidos mecanismos de defesa e regulação. Os elementos químicos são utilizados em formas químicas estáveis nas condições em que são usadas. As condições ambientais, que consideramos "normais" (por exemplo 1 atm, 37 ${ }^{\circ} \mathrm{C}, \mathrm{pH}=7$, salinidade - água do mar, potencial de oxidação-redução meio aquoso oxigenado), podem, no entanto, ser consideravelmente alargadas.

Tabela 1 - O ambiente e a Vida - Condições limitantes

\begin{tabular}{lll}
\hline Parâmetro & Limite inferior & Limite superior \\
\hline Temperatura & $-18^{\circ} \mathrm{C}$ (fungos, bactérias) & $>100^{\circ} \mathrm{C}$ (bactérias) \\
potencial oxidação-redução & $-450 \mathrm{mV}$ (bactérias) & $+850 \mathrm{mV}$ (bactérias) \\
PH & Próximo de 0 (Thiobacillus) & 13 (bactérias) \\
Pressão & Próximo de zero & 1400 atm \\
Salinidade & (bactérias várias) & (bactérias fossas abissais) \\
& água bidestilada & Salmoura \\
& (bactérias heterotróficas) & (bactérias halófilas) \\
\hline
\end{tabular}

Assim considera-se que os seres vivos se desenvolvem em dois meios distintos: um meio exterior sujeito a variações mais ou menos acentuadas e um meio interior (i.e. sangue, outros fluidos) que são mantidos em condições de controlo estrito, através de mecanismos de regulação desenvolvidos para o efeito.
Grandes massas de água oferecem condições particularmente estáveis (relembrar, por exemplo, o elevado calor específico). Além disso, o meio aquoso é propício à ocorrência de reacções químicas, transporta nutrientes e contém gases dissolvidos que contêm elementos químicos essenciais (por exemplo $\mathrm{CO}_{2}$ e $\mathrm{O}_{2}$ ). A água foi, portanto, o meio de escolha para a origem da vida e não é, por isso, surpreendente verificar que existe uma correlação entre a composição relativa de iões na água do mar, nos fluidos do corpo humano e nos meios salinos usados em medicina para manter funcionais órgãos e tecidos. 


\section{C - A SELECÇÃO DOS ELEMENTOS QUÍMICOS PELOS SISTEMAS BIOLÓGICOS}

Os sistemas biológicos têm de captar, e, em muitos casos, concentrar, determinados elementos químicos de que necessitam, rejeitando outros que lhes são prejudiciais. Em princípio pode-se dizer que actuam segundo as regras convencionais da Química Analítica e Inorgânica. Portanto a utilização e gestão económica dos recursos disponíveis é uma etapa inicial a considerar.

\section{Abundância}

O aspecto abundância é importante: quanto maior for o teor de um dado elemento no meio exterior mais fácil, em princípio, será a sua captação. Este teor depende da abundância intrínseca e da disponibilidade do elemento (acessibilidade ao sistema biológico). Por exemplo $\mathrm{Na}, \mathrm{K}, \mathrm{Mg}$ e Ca são mais abundantes do que outros elementos alcalinos e alcalino- terrosos e portanto muito utilizados. Os sistemas biológicos obtêm os elementos químicos que necessitam a partir do meio em que se desenvolvem (solos, meios aquáticos, atmosfera, etc.). Em geral no sistema solar (e no planeta Terra) verifica-se que a abundância de um dado elemento decresce exponencialmente com o número atómico, sendo os elementos mais pesados os menos abundantes. Logo a utilização de elementos mais leves segue este critério.

Tabela 2 - Comparação de Análises Elementares - Universo, Terra, Água do Mar e Corpo Humano (em \% do número total de átomos)

\begin{tabular}{|c|c|c|c|c|c|c|c|}
\hline \multicolumn{2}{|c|}{ Universo } & \multicolumn{2}{|c|}{ Terra } & \multicolumn{2}{|c|}{ Água do Mar } & \multicolumn{2}{|c|}{ Corpo Humano } \\
\hline & 91 & & 47 & $\mathrm{H}$ & 66 & $\mathrm{H}$ & 63 \\
\hline $\mathrm{He}$ & 9.1 & & 28 & $\mathrm{O}$ & 33 & $\mathrm{O}$ & 25.5 \\
\hline & 0.057 & $\mathrm{Al}$ & 7.9 & $\mathrm{Cl}$ & 0.33 & C & 9.5 \\
\hline & 0.042 & $\mathrm{Fe}$ & 4.5 & $\mathrm{Na}$ & 0.28 & $N$ & 1.4 \\
\hline C & 0.021 & $\mathrm{Ca}$ & 3.5 & $\mathrm{Mg}$ & 0.033 & $\mathrm{Ca}$ & 0.31 \\
\hline $\mathrm{Si}$ & 0.003 & $\mathrm{Na}$ & 2.5 & $S^{\circ}$ & 0.017 & $P$ & 0.22 \\
\hline & 0.003 & K & 2.5 & $\mathrm{Ca}$ & 0.006 & $\mathrm{Cl}$ & 0.03 \\
\hline $\mathrm{Mg}$ & 0.002 & $\mathrm{Mg}$ & 2.2 & K & 0.006 & K & 0.06 \\
\hline $\mathrm{Fe}^{\circ}$ & 0.002 & $\mathrm{Ti}^{\circ}$ & 0.46 & C & 0.0014 & $\mathrm{~S}$ & 0.05 \\
\hline \multirow[t]{2}{*}{$\mathrm{S}$} & 0.001 & & 0.22 & $\mathrm{Br}$ & 0.0005 & $\mathrm{Na}$ & 0.03 \\
\hline & & $\mathrm{C}$ & 0.19 & & & $\mathrm{Mg}$ & 0.01 \\
\hline
\end{tabular}

Este conceito (abundância) não se aplica aos compostos de silício e de carbono. O silício é muito mais abundante do que o carbono mas menos utilizado. Esta escolha está relacionada com o ponto a seguir discutido, a disponibilidade. Na realidade os óxidos de silício são muito insolúveis em meio aquoso, enquanto que $\mathrm{O}_{2} \mathrm{CO}_{2}$ é facilmente disponível aos seres vivos pela sua elevada solubilidade em água (carbonatos). Além disso, a química de carbono, possibilitando a formação de ligações simples, duplas e triplas, permite a utilização deste elemento em blocos construtores extremamente versáteis do ponto de vista estrutural (conceito de versatilidade química).

\section{Disponibilidade}

Conforme referimos, não só a abundância dos elementos essenciais condiciona a possibilidade da sua utilização pelos sistemas biológicos. Estes elementos têm de estar disponíveis, numa forma que possibilite a sua incorporação. A forma química depende do $\mathrm{pH}$ e do potencial redox e vai determinar a sua maior ou menor solubilidade, possibilidade de ionização, formação de espécies complexas, estabilidade de estados redox, etc. Relembrar que o ião sódio existirá numa forma estável $\left(\mathrm{Na}^{+}\right)$e nunca sob a forma de sódio metálico em solução aquosa. Na Tabela indicam-se algumas formas nas quais os principais elementos biológicos podem ocorrer em meios aquosos. Assim as condições ambientais podem impor severas restrições às formas químicas disponíveis aos sistemas biológicos.

Um outro conceito importante é que não se deve subestimar a versatilidade e a "tenacidade" dos siste-

Tabela 3 - Formas nas quais os principais elementos biológicos ocorrem em meio aquoso

\begin{tabular}{lll}
\hline catiões & aniões & neutros \\
\hline $\mathrm{H}_{3} \mathrm{O}^{+}, \mathrm{NH}_{4}^{+}$ & $\mathrm{HCO}_{3}^{-}, \mathrm{CO}_{3}^{2-}, \mathrm{NO}_{3}^{-}$ & $\mathrm{B}(\mathrm{OH})_{3}$ \\
$\mathrm{Na}^{+}, \mathrm{K}^{+}$ & $\mathrm{H}_{2} \mathrm{PO}_{4}^{-}, \mathrm{HPO}_{4}^{2-}$ & $\mathrm{CO}_{2}, \mathrm{SiO}_{2}$ \\
$\mathrm{Mg}^{2+}, \mathrm{Ca}^{2+}$ & $\mathrm{OH}^{-}, \mathrm{F}^{-}, \mathrm{Cl}^{-}, \mathrm{Br}^{-}, \mathrm{I}^{-}, \mathrm{SO}_{4}^{2-}$ & $\mathrm{N}_{2}, \mathrm{NH}_{3}, \mathrm{O}_{2}$ \\
\hline
\end{tabular}


Tabela 3 - (Continuação)

\begin{tabular}{|c|c|c|c|c|}
\hline Metais (ex.) & espécies químicas principais & & & \\
\hline $\mathrm{Al} 3+$ & $\mathrm{Al}(\mathrm{OH})_{3}$ & & & \\
\hline $\mathrm{Cr}^{3+}$ & $\mathrm{Cr}(\mathrm{OH})^{2+}$ & $\mathrm{CrO}_{2}^{-}$ & & \\
\hline $\mathrm{Mn}^{2+}$ & $\mathrm{MnCl}^{+}$ & $\mathrm{MnSO}_{4}$ & & \\
\hline $\mathrm{Fe}^{2+} \mathrm{Fe}^{3+}$ & $\mathrm{Fe}(\mathrm{OH})^{+}, \mathrm{Fe}(\mathrm{OH})_{3}$ & $\mathrm{FeCl}^{-}, \mathrm{Fe}(\mathrm{OH})_{2}^{+}$ & & \\
\hline $\mathrm{Co}^{2+}$ & $\mathrm{CoCl}^{+}$ & $\mathrm{CoCO}_{3}$ & $\mathrm{CoSO}_{4}$ & \\
\hline $\mathrm{Ni}^{2+}$ & $\mathrm{NiCl}^{+}$ & $\mathrm{NiCO}_{3}$ & $\mathrm{NiSO}_{4}$ & \\
\hline $\mathrm{Cu}^{2+}$ & $\mathrm{Cu}(\mathrm{OH}) \mathrm{Cl}$ & $\mathrm{CuCO}_{3}$ & $\mathrm{CuCl}^{+}$ & $\mathrm{Cu}(\mathrm{OH})^{+}$ \\
\hline $\mathrm{Zn}^{2+}$ & $\mathrm{ZnCl}^{+}$ & $\mathrm{ZnCl}_{2}$ & $\mathrm{Zn}(\mathrm{OH}) \mathrm{Cl}$ & \\
\hline $\mathrm{Mo}^{6+}$ & $\mathrm{MoO}_{4}^{2-}$ & & & \\
\hline $\mathrm{Cd}^{2+}$ & $\mathrm{CdCl}_{2}$ & $\mathrm{CdCl}^{+}$ & $\mathrm{CdCl}_{3}^{2-}$ & \\
\hline $\mathrm{Hg}^{2+}$ & $\mathrm{HgCl}_{4}^{-}$ & $\mathrm{HgCl}_{3} \mathrm{Br}^{2-}$ & $\mathrm{HgICl}_{3}^{-}$ & \\
\hline $\mathrm{Pb}^{2+}$ & $\mathrm{PbCl}_{2}$ & $\mathrm{PbCl}^{-}$ & $\mathrm{Pb}(\mathrm{OH})^{+}$ & $(\mathrm{Pb}(\mathrm{OH}) \mathrm{Cl}$ \\
\hline
\end{tabular}

mas biológicos. Quando um dado elemento apresenta propriedades únicas, pode ocorrer uma procura selectiva e concentração de certos elementos. Exemplos ilustrativos são a captação selectiva de vanádio e molibdénio.

Concentração e captura selectiva de certos elementos

Os elementos químicos requeridos pelos seres vivos têm de ser incorporados. O mecanismo de absorção pode numa primeira interpretação ser considerado como um processo de difusão simples regulado pela pressão osmótica mantida no interior a um valor inferior ao do exterior, através de uma utilização metabólica constante dos elementos adsorvidos. No entanto, verifica-se que em muitos casos ocorre uma acumulação passiva das espécies absorvidas contra o gradiente de concentração, atingindo valores no interior superiores aos detectados no exterior (conceitos de transporte passivo, processo dependente e energia e transporte activo (utilização de translocadores).

O problema da captura, transporte e inserção de metais de transição em proteínas e enzimas é um campo de investigação activo com larga contribuição da biologia molecular. Um exemplo que pode ser escolhido é o da inserção do ferro na estrutura do hemo levada a cabo pela enzima ferroquelatase. Outros tópicos de grande interesse: a mobilização biológica de níquel e molibdénio e o transporte e acumulação de ferro e sua implicações em regulação metabólica.

\section{D - AS FUNÇÕES \\ DOS ELEMENTOS QUÍMICOS NOS SISTEMAS BIOLÓGICOS}

Interacção dos iões metálicos com os sistemas biológicos

Uma discussão e compreensão da utilização (escolha), da estrutura e da reactividade de iões metálicos como constituintes de centros catalíticos de enzimas pode utilizar como base muitos dos conceitos da Química Inorgânica sobre coordenação e geometria de metais inseridos em compostos de coordenação. A constante de associação de metais ao sistema biológico e a facilidade de alteração de estado de oxidação são determinantes na construção dos centros activos usados.

Por exemplo o número de átomos coordenantes que podem ser doadas pelos sistemas biológicos é restrito (O, S, N e P). No caso de enzimas e proteínas a ligação de metais a cadeias polipeptídicas é feita pelos grupos laterais dos amino-ácidos, que fornecem potenciais átomos coordenantes tais como - $\mathrm{COO}-,-\mathrm{NH}_{2}$, >NH, -S-. A preferência de um dado metal por um dado ligando está relacionada com a estrutura electrónica do metal e características do ligando (ver Apendice C).

As geometrias apresentadas variam dentro das convencionalmente encontradas em compostos inorgâni-

Tabela 4 - Ligandos preferidos por diversos iões metálicos em biologia

\begin{tabular}{ll}
\hline Iões metálicos & Ligandos biológicos utilizados \\
\hline $\mathrm{Na}^{+} \mathrm{K}^{+}$ & Ligandos oxigenados neutros ou com carga -1 \\
$\mathrm{Mg}^{2+} \mathrm{Mn}^{2+}$ & Grupos carboxilatos, fosfato e dadores azotados (porfirinas) \\
$\mathrm{Ca}^{2}$ & Grupos carboxilato e fosfato \\
$\mathrm{Fe}^{2+}$ & Grupos $-\mathrm{S}$ - e grupos $>\mathrm{NH}$ (imidazol, porfirinas) \\
$\mathrm{Fe}^{3+} \mathrm{Co}^{3+}$ & Fenóis (tirosina), carboxilatos, porfirinas \\
$\mathrm{Cu}^{+}$ & Grupos $-\mathrm{S}$ - (cisteína) e aminas aromáticas \\
$\mathrm{Cu}^{2+}$ & Aminas, imidazol, grupos $>\mathrm{N}$ - \\
$\mathrm{Zn}^{2+}$ & Aminas, imidazol, grupos $-\mathrm{S}-$ \\
$\mathrm{Ag}^{+}, \mathrm{Hg}^{2+}, \mathrm{Cd} 2+$ & Grupos $-\mathrm{S}$ - e aminas \\
$\mathrm{Pb}^{2+}$ & Grupos carboxilato $-\mathrm{S}-$ \\
\hline
\end{tabular}


Tabela 5 - Iões metálicos e geometrias mais frequentes

\begin{tabular}{ll}
\hline ião metálico & geometrias mais frequentes \\
\hline $\mathrm{Cu}^{2+}$ & Tetragonal $>$ n.c. $5>$ Tetraédrica \\
$\mathrm{Ni}^{2+}$ & Octaédrica $>$ restantes \\
$\mathrm{Co}^{2+}$ & Octaédrica $>$ Tetraédrica $>$ restantes \\
$\mathrm{Zn}^{2+}$ & Tetraédrica $>$ Octaédrica \\
$\mathrm{Mn}^{2+}$ & Octaédrica $>$ restantes \\
$\mathrm{Fe}^{3+}$ & Octaédrica $>$ Tetraédrica \\
\hline
\end{tabular}

cos (em geral números de coordenação 4 - tetraédrico e quadrangular plano e 6-octaédrico, mas estruturas pentacoordenadas são também observadas).
Tipos de funções: classificação dos elementos biológicos

A função desempenhada pelos elementos químicos disponibilizados e utilizados pelos sistemas biológicos está intimamente relacionada com o modo de interacção com os ligandos biológicos assim como as propriedades intrínsecas desses elementos. Estabilidade, preferência por certos li-

Tabela 6 - Algumas características dos elementos metálicos

\begin{tabular}{lllll}
\hline propriedade & $\mathrm{Na}^{+}, \mathbf{K}+$ & $\mathbf{M g}^{++}, \mathbf{C a}^{2+}$ & $\mathbf{Z n}^{2+}, \mathbf{N i}^{2+}$ & $\mathbf{F e}, \mathbf{C u}, \mathbf{C o}, \mathbf{M o}, \mathbf{W}, \mathbf{M n}$ \\
\hline Estabilidade com ligandos biológicos & muito baixa & baixa/média & elevada & elevada \\
Tipo de ligando & $\mathrm{O}$ & $\mathrm{O}$ & $\mathrm{N}, \mathrm{S}$ & $\mathrm{N}, \mathrm{S}, \mathrm{O}\left(\mathrm{Fe}{ }^{3+}\right)$ \\
Estados de oxidação & +1 (fixo) & +2 (fixo) & +2 (fixo) & variável \\
Mobilidade & muito móvel & semi-móvel & estático & estático \\
\hline
\end{tabular}

gandos e possibilidade de alternância entre diferentes estados de oxidaçãoredução vão ser determinantes nas funções a desempenhar. Alguns exemplos são ilustrados na Tabela 6 .

Os elementos químicos podem desempenhar diferentes funções que podem ser classificadas de um modo geral em funções electroquímicas, estruturais, catalíticas e outras de acordo com as propriedades intrínsecas apresentadas. De um modo simplificado, na Tabela 7 pretende-se agrupar e classificar os elementos químicos com base nas suas funções principais.
Funções electroquímicas

Os elementos com funções electroquímicas ocorrem nos meios biológicos na forma de catiões $\left(\mathrm{Na}^{+}, \mathrm{K}+\right.$, $\left.\mathrm{Ca}^{2+}, \mathrm{Mg}^{2+}\right)$ e aniões $\left(\mathrm{Cl}^{-}, \mathrm{NO}_{3}{ }^{-}\right.$, $\mathrm{HCO}_{3}-, \mathrm{SO}_{4}{ }^{2-}, \mathrm{H}_{2} \mathrm{PO}_{4}^{-}$).

Em geral as células são ricas em potássio e magnésio e pobres em cál-

Tabela 7 - Funções Principais dos Elementos Químicos de Interesse Biológico

\begin{tabular}{|c|c|c|c|}
\hline Tipo de função & Elemento & Estado químico & Actividade biológica \\
\hline $\begin{array}{l}\text { Funções electroquímicas } \\
\text { de controlo osmótico } \\
\text { e de transporte de corrente }\end{array}$ & $\begin{array}{l}\mathrm{Na}, \mathrm{K}, \mathrm{Cl},(\mathrm{Mg}) \\
\text { (Ca), sulfato }\end{array}$ & $\begin{array}{l}\text { Em solução aquosa } \\
\text { na forma de iões livres }\end{array}$ & $\begin{array}{l}\text { Transmissão de mensagens } \\
\text { Produção de energia metabólica }\end{array}$ \\
\hline Formação de estruturas & $\begin{array}{l}\mathrm{H}, \mathrm{O}, \mathrm{C}, \mathrm{N}, \mathrm{P}, \mathrm{S} \\
\mathrm{Si}, \mathrm{F}, \mathrm{Ca},(\mathrm{Mg})\end{array}$ & $\begin{array}{l}\text { Compostos orgânicos } \\
\text { e inorgânicos pouco solúveis } \\
\text { (fosfato e carbonato de cálcio, } \\
\text { silicatos) }\end{array}$ & $\begin{array}{l}\text { Tecidos, esqueletos } \\
\text { membranas, conchas, etc. }\end{array}$ \\
\hline Catálise ácida & $\mathrm{Zn}, \mathrm{Ni}$ & enzimas & $\begin{array}{l}\text { Degradação de proteínas } \\
\text { Hidrólise de ureia }\end{array}$ \\
\hline $\begin{array}{l}\text { Catálise de reacções } \\
\text { de oxidação redução }\end{array}$ & $\begin{array}{l}\mathrm{Fe}, \mathrm{Cu}, \mathrm{Mn}, \mathrm{Mo} \\
\text { W, Se, Ni, V, Co }\end{array}$ & enzimas & $\begin{array}{l}\text { Reacções com oxigénio } \\
\text { Fixação de azoto } \\
\text { Produção de hidrogénio } \\
\text { Redução de aldeídos } \\
\text { Fotólise da água } \\
\text { Desintoxicação, etc. }\end{array}$ \\
\hline Outras funções & $\begin{array}{l}\mathrm{Fe}, \mathrm{Cu} \\
\mathrm{Ca}, \mathrm{Mg} \\
\text { lodo } \\
\mathrm{O}_{2}, \mathrm{~N}_{2}, \mathrm{CO}_{2}\end{array}$ & em proteínas & $\begin{array}{l}\text { Transporte de Oxigénio } \\
\text { Activação de enzimas } \\
\text { Controle hormonal } \\
\text { Artifícios de flutuação }\end{array}$ \\
\hline
\end{tabular}


cio e sódio relativamente ao meio em que se encontram. Este diferencial de concentrações tem paralelo com o que se passa em pilhas electroquímicas e está associado à produção de energia metabólica, uma das funções possíveis para estes elementos. A transmissão de estímulos nervosos está ligada à perda de potássio e ao ganho de sódio e o fenómeno de contracção muscular está relacionado com os níveis de cálcio e magnésio. Estes elementos desempenham ainda um papel importante no estabelecimento de condições de electroneutralidade, pois muitas moléculas biológicas encontram-se ionizadas a $\mathrm{pH}$ neutro tais como carboxilatos, fosfato, amónia, etc.

\section{Funções estruturais e de suporte}

As macromoléculas biológicas que temos vindo a discutir são polímeros de moléculas contendo como unidades principais amino-ácidos, hidratos de carbono, nucleótidos e derivados de ácidos gordos. Estas unidades são moléculas orgânicas constituídas pelos quatro elementos principais: $\mathrm{H}, \mathrm{C}$, O e N e em alguns casos S e P.

Proteínas (polímeros de aminoácidos) e polissacáridos (polímeros de hidratos de carbono) bem como derivados de ácidos gordos estão ligados à forma e estrutura dos seres vivos, por serem constituintes de membranas celulares, tecidos, vasos, cartilagens, pelos, etc. $\mathrm{Mg}^{2+}$ and $\mathrm{Ca}^{2+}$ podem associar-se de modo a aumentar a estabilidade da estrutura.

As estruturas sólidas são normalmente constituídas por hidroxi-apatite $\left(\mathrm{Ca}_{10}\left(\mathrm{PO}_{4}\right)_{6}(\mathrm{OH})_{2}\right)$ (ossos e dentes) e carbonato de cálcio (conchas, corais, cascas de ovos, etc.). A sílica está também envolvida na formação e estruturas sólidas tais como exo-esqueletos de animais marinhos, espículas de plantas e associado à formação dos ossos nos vertebrados. Outros compostos mais raramente usados em estruturas sólidas são o fluoreto de cálcio e os sulfatos de bário e estrôncio.

\section{Funçōes catalíticas}

As reacções biológicas são em geral catalisadas por determinadas proteínas designadas por enzimas.
Muitas destas enzimas contêm metais ou complexos de metais fortemente associados (metalo-proteínas) ou são activadas por metais não ligados às proteínas (coordenação lábil). A actividade catalítica é muitas vezes relacionada com a presença de certos elementos químicos: enzimas activadas por metais e metalo-enzimas. As propriedades específicas podem ainda depender da conformação da proteína e da presença de certos grupos funcionais colocados em posições estruturais correctas e estratégicas, a fim de levar a cabo uma da reacção.

\section{Enzimas activadas por metais}

O ião magnésio é um elemento frequentemente usado como activador. Outros elementos usados (e que podem por vezes substituir aquele ião) são o cálcio, o sódio e o potássio (e o ferro e manganês divalentes). Mesmo certas metalo-enzimas (contendo metais de transição no centro catalítico) podem requerer activadores metálicos (exemplo cálcio) como é o caso de certas peroxidases contendo ferro hémico.

\section{Metalo-enzimas}

Este é o grupo de maior interesse dado a sua especificidade reaccional. O metal (centro activo) está associado fortemente à proteína ou a uma molécula pequena, diferente da proteína, mas igualmente ligada a esta (grupo prostético).
Ferro, cobre, molibdénio, zinco, níquel, cobalto, tungsténio, manganês são frequentemente utilizados. $\mathrm{O}$ grupo das metalo-enzimas é numeroso e variado e interveniente em reacções chave em biologia.

Duas funções principais são atribuídas a estes centros catalíticos:

i) catálise de reacções ácido-base (ácidos de Lewis): zinco e níquel.

ii) catálise de reacções de oxidação-redução (transferência de electrões) - utilização de metais que podem variar de estado de oxidação: $\mathrm{Cu}(\mathrm{II}) / \mathrm{Cu}(\mathrm{I}), \mathrm{Fe}(\mathrm{IV}) / \mathrm{Fe}(\mathrm{III}) / \mathrm{Fe}(\mathrm{II})$, $\mathrm{Mo}(\mathrm{VI}) / \mathrm{Mo}$ ( V ) / Mo ( I V ). $\mathrm{Ni}(\mathrm{III}) / \mathrm{Ni}(\mathrm{II}) .{ }^{1}$

Um dos exemplos mais frequentemente usados como grupo prostético é a protoporfirina, molécula orgânica que proporciona quatro átomos coordenantes numa estrutura quandrangular plana e onde os ligandos axiais ( $5^{\mathrm{a}}$ e $6^{\mathrm{a}}$ posições de coordenação) são ocupados por ligandos variáveis formando uma estrutura octaédrica.

A presença de um ligando lábil na $6^{\mathrm{a}}$ posição (uma molécula de água) permite uma vastidão de funções para a mesma estrutura básica.

Variações estruturais deste tema com Co (vitamina $\mathrm{B}_{12}$ ), Mg (clorofila) ou $\mathrm{Ni}$ (factor $\mathrm{F}_{430}$, produção de $\mathrm{CH}_{4}$ ) são mais uma demonstração de versatilidade estrutural (ver Fig. 1).

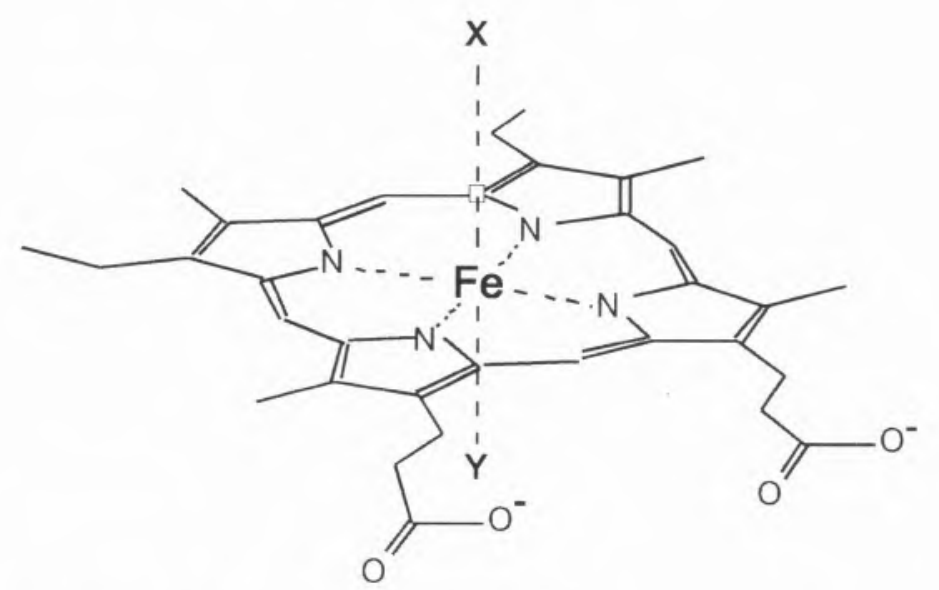

Fig. 1 - Versatilidade de coordenação da estrutura do hemo. 
Tabela 8 - Variabilidade de Coordenação em Proteínas Hémicas

\begin{tabular}{lll}
\hline Proteína & Ligandos axiais & Função \\
\hline citocromo c & $\mathrm{HIS}, \mathrm{MET}$ & Transferência electrónica \\
citocromo b & $\mathrm{HIS}, \mathrm{HIS}$ & Transferência electrónica \\
hemoglobina & $\mathrm{HIS}, \mathrm{H}_{2} \mathrm{O}$ & Transporte de oxigénio \\
peroxidase & $\mathrm{HIS}, \mathrm{H}_{2} \mathrm{O}\left(\mathrm{H}_{2} \mathrm{O}_{2}\right)$ & A- $\mathrm{H}_{2}+\mathrm{H}_{2} \mathrm{O}_{2} \rightarrow \mathrm{A}+2 \mathrm{H}_{2} \mathrm{O}$ \\
cloroperoxidase & $\mathrm{CIS}, \mathrm{H}_{2} \mathrm{O}\left(\mathrm{H}_{2} \mathrm{O}_{2}\right)$ & A- $\mathrm{H}^{+\mathrm{X}-}+\mathrm{H}_{2} \mathrm{O}_{2} \rightarrow \mathrm{A}-\mathrm{X}+\mathrm{H}_{2} \mathrm{O}$ \\
catalase & TIR, $\mathrm{H}_{2} \mathrm{O}\left(\mathrm{H}_{2} \mathrm{O}_{2}\right)$ & $2 \mathrm{H}_{2} \mathrm{O}_{2} \rightarrow 2 \mathrm{H}_{2} \mathrm{O}+\mathrm{O}_{2}$ \\
\hline
\end{tabular}

Outro exemplo que ilustra bem a versatilidade de construção de centros activos em proteínas é o caso dos centros ferro-enxofre (Fig. $2)$, constituídos por ferro numa geometria tetraédrica (bloco construtor) envolvendo dois tipos de enxofre (enxofre inorgânico em ponte e enxofre de resíduo cisteína que ligam o agregado à cadeia polipeptídica).

\section{Outras Funções}

Os elementos químicos desempenham ainda muitas outras funções tais como: transporte de gases (hemoglobina e hemocianina), armazenagem de metais (metalo-tioninas), absorção de luz no processo fotossintético (clorofila - Mg e agregados contendo $\mathrm{Mn}$ ), produção e utilização de gases, etc. (ver Tabela 9).

\section{Rubredoxina $\left[\mathrm{FeS}_{4}\right]$}

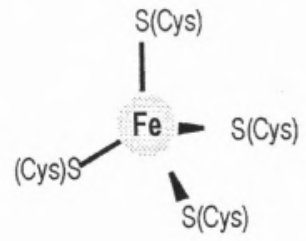

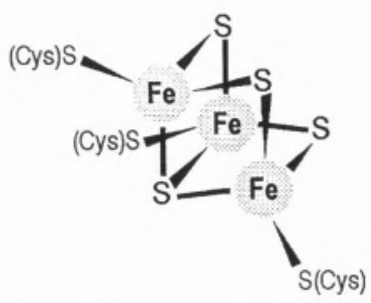

[3Fe-4S]

\section{2[Fe-2S]}

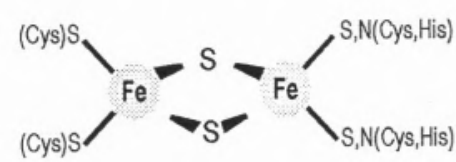

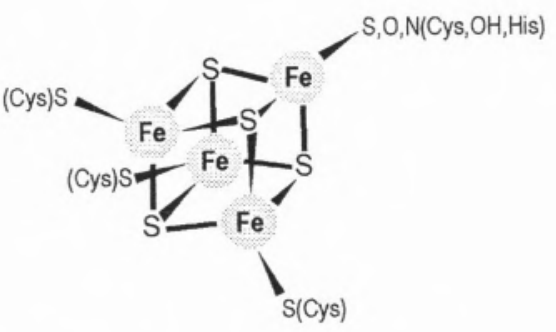

$4[\mathrm{Fe}-4 \mathrm{~S}]$

Fig. 2 - Centros ferro-enxofre.

Tabela 9 - Algumas metalo-enzimas e enzimas activadas por metais

\begin{tabular}{lll}
\hline Enzimas activadas por metais & Tipo de reacção & Metal \\
\hline $\begin{array}{l}\text { ATPases } \\
\text { Enolases }\end{array}$ & $\begin{array}{l}\text { Transferência grupo fosfato } \\
\text { Desidratação } \\
\text { Descarbarboxilação }\end{array}$ & $\mathrm{Mg}, \mathrm{Ca}$ \\
\hline Metalo-proteínas & Tipo de reacção & $\mathrm{Mg}$ \\
\hline Carboxipeptidase & Hidrólise de peptidios & Metal \\
Anidrase carbónica & Hidratação de $\mathrm{CO}_{2}$ & $\mathrm{Zn}$ \\
Urease & Hidrólise de ureia & $\mathrm{Zn}$ \\
Carboxitransfoforilase & Transferência grupo fosfato & $\mathrm{Ni}$ \\
ATP sulfurilase & Activação sulfato & $\mathrm{Co}$ \\
Lacase & Oxidação & $\mathrm{Co}$ \\
Oxidase de citocromo c & Oxidação & $\mathrm{Cu}$ \\
Catalase & Decomposição $\mathrm{H}_{2} \mathrm{O}_{2}$ & $\mathrm{Fe}, \mathrm{Cu}$ \\
Ferredoxina & Transferência electrónica & $\mathrm{Fe}$ \\
Oxidase de xantina & Oxidação da xantina & $\mathrm{Fe}$ \\
Óxido-redutase de aldeído & Conversão:aldeído a ácido carboxílico & $\mathrm{Fe} \mathrm{Mo,} \mathrm{Fe}$ \\
Hidrogenase & Produção/consumo $\mathrm{H}_{2}$ & $\mathrm{Mo}, \mathrm{Fe} \mathrm{e} \mathrm{W,} \mathrm{Fe}$ \\
\hline
\end{tabular}




\section{E - ENZIMAS E ELEMENTOS METÁLICOS}

Determinadas proteínas globulares têm como função principal a catálise das reacções biológicas. Os oligo-elementos têm importantes funções: alguns são activadores de enzimas e outros fazem mesmo parte integrante do centro activo de enzimas, que são então designadas por metalo-enzimas.

Neste capítulo são examinados aspectos estrutura-função.

\section{Catalisadores biológicos}

Como qualquer catalisador, as enzimas não alteram as condições termodinâmicas de uma dada reacção, isto é, a relação produto/reagente no equilíbrio. Actuam, no entanto, sobre a cinética das reacções, aumentando as velocidades reaccionais (reacção directa e inversa) tornando possíveis reacções que seriam muito lentas na ausência de um catalisador. Dois aspectos importantes devem ser retidos: i) as reacções catalisadas por enzimas são altamente específicas, catalisando apenas uma reacção ou um tipo de reacções e ii) o poder catalítico amplificado pelo facto de um substrato de uma enzima ser o produto de uma reacção catalisada anteriormente (ex. cadeias respiratórias, fotossíntese, etc.).

\section{Nomenclatura}

O sistema de nomenclatura é baseado na especificidade reaccional. O nome da enzima é construído a partir da reacção catalisada, adicionando o sufixo ase .

\section{Exemplos}

isomerase - reacções de isomerização

hidrolase - reacções de hidrólise lipase - reacções sobre lípidos hidrogenase - produção/consumo de hidrogénio

redutase de nitr(a)ito - reacção de redução de nitr(a)ito

\section{Mecanismo}

O mecanismo de actuação de enzimas envolve em geral a formação de um complexo ou associação enzima-substrato: cada enzima tem portanto um centro activo com uma conformação que lhe permite um reconhecimento específico de um dado reagente. Este ajuste enzima-substrato é muitas vezes designado pelo termo mecanismo chave-fechadura.

A actividade enzimática pode ser afectada por substâncias designadas por inibidores que bloqueiam o centro catalítico por se ligarem irreversivelmente ou por induzirem alterações conformacionais, deformando o centro catalítico, impedindo a ligação de substrato. Em geral os inibidores estão relacionados estruturalmente com os substratos.
A indução de alterações conformacionais pode ser aproveitada com fins positivos (alosteria) - um bom exemplo a discutir é a ligação de oxigénio à hemoglobina, bem documentado na literatura.

As enzimas requerem muitas vezes a presença de activadores. Diversos iões (e seus complexos) bem como moléculas orgânicas de baixa massa molecular (vitaminas, nucleótidos) são usados (co-enzimas). Grupos prostéticos designam estruturas moleculares ligadas permanentemente às enzimas (caso da porfirina-Fe em citocromos).

É de salientar que o processo de catálise enzimática por metalo-proteínas resulta de uma acção concertada entre a cadeia polipeptídica e o centro catalítico contendo o metal. Um exemplo ilustrativo é a comparação da actividade enzimática da catalase (que transforma $\mathrm{H}_{2} \mathrm{O}_{2}$ ) e dos seus elementos constitutivos:

$\begin{array}{lc}\text { catalase } & 10^{6} \\ \text { Fe-Porfirina } & 1 \\ \text { Proteína } & 0\end{array}$

Metalo-enzimas e enzimas activadas por iões metálicos

A Tabela 10 apresenta alguns exemplos representativos dos grupos de enzimas activados por metais e metalo-enzimas (com ênfase para os elementos metálicos presentes e tipo de reacção envolvida).

Tabela 10 - Exemplos de enzimas representativos (lista não exaustiva)

\begin{tabular}{ll}
\hline Enzima & Função \\
\hline Zinco & \\
Fosfatase alcalina & Hidrólise de fosfatos \\
Anidrase carbónica & Hidratação do $\mathrm{CO}_{2}$ \\
Carboxipeptidase & Hidrólise de proteínas \\
Amilase & Hidrólise de polisacàridos \\
Polimerase do ADN/ARN & Replicação de A.N. \\
Desidrogenase do alcóol & Oxidação de alcóois \\
& \\
Cobre & Redução de $\mathrm{O}_{2}$ a $\mathrm{H}_{2} \mathrm{O}$ \\
Oxidase do citocromo & Oxidação de fenóis \\
Lacase & n.d. \\
Ceruplasmina & Transporte de $\mathrm{O}_{2}$ \\
Hemocianina & Oxidação de ascorbato \\
Oxidase do ácido ascórbico & Oxidação alcóois primários a aldeídos \\
Oxidase da galactose & Transferência electrónica \\
Proteínas azúis & Dismutação do ião superóxido \\
Dismutase do superóxido & \\
\hline
\end{tabular}


Tabela 10 - (continuação)

\begin{tabular}{ll}
\hline Enzima & Função \\
\hline Ferro & \\
Hemoglobina & Transporte de oxigénio \\
Transferrina & Transporte de ferro \\
Rubredoxina e Ferredoxina (Fe-S) & Transferência electrónica \\
Citocromos (hemo) & Transferência electrónica \\
Peroxidase (hemo) & Utilização de $\mathrm{H}_{2} \mathrm{O}_{2}$ \\
Catalase (hemo) & Decomposiçao de $\mathrm{H}_{2} \mathrm{O}_{2}$
\end{tabular}

\section{Molibdénio}

Oxidase da xantina

Oxidase do aldeído

Oxidação de xantina a ácido úrico

Oxidase de sulfito

Oxidação de aldeídos

Nitrogenase

Redutase de nitrato

Oxidação de sulfito a sulfato

Fixação de azoto

Redução de nitrato a nitrito

Desidrogenase de formato

Formato $\longrightarrow \mathrm{CO}_{2}$

\section{Níquel}

Urease

Hidrogenase

Hidrólise de ureia

Produção/consumo $\mathrm{H}_{2}$

\footnotetext{
Funções possíveis dos centros metálicos envolvidos em catálise são:

i) aproximação proteína - substrato; formação de um complexo

ii) efeitos indutivos facilitando formação e quebra de ligações químicas, incluíndo catálise ácida

iii) imposição de uma conformação na proteína (efeito estereoquímico)

iv) transferência electrónica (alteração estado de oxidação, ex. $\mathrm{Fe}^{2+} \mathrm{e} \mathrm{Fe}^{3+}$ )

v) efeitos alostéricos, por ex. variação do número de coordenação em proteínas hémicas, substituição de ligandos.
}

\section{Um aspecto importante: complementaridade entre técnicas estruturais e biologia molecular}

A determinação de estruturas de metalo-enzimas é um problema complexo que requer o consórcio de técnicas várias (RMN, RPE, EXAFS, raios-X). Em geral estas técnicas requerem quantidades importantes de material puro e o ajuste de condições de cristalização pode ser uma etapa lenta. Para se resolver uma estrutura tridimensional de uma proteína por RMN (limitado a cerca de $20 \mathrm{kDa}$ ) ou por cristalografia, certas condições devem ser verifi-cadas:

- existência de proteína pura em quantidade importante

- conhecimento da sequência de amino-ácido

- marcação isotópica pode ser requerida para estudos de $\mathrm{RMN}$ assim como a obtenção de derivados de átomos pesados para estudos de difracção por raios-X.

As técnicas de biologia molecular tornaram-se aliadas poderosas dos métodos espectroscópico, pois:

- permitem obter material bio-

lógico em quantidade importante

- facilitam a determinação de estruturas primárias

- introduzem mutações selectivas em amino-ácidos e inserções e delecções na sequência primária

- permitem a obtenção facilita-

da de material marcado com ${ }^{57} \mathrm{Fe}$, ${ }^{15} \mathrm{~N},{ }^{13} \mathrm{C}$

Recentemente pela conjugação destas técnicas um elevado número de estruturas de metaloproteínas foram reveladas permitindo clarificar aspectos estruturais cruciais para a compreensão da função:

Respiração e utilização de

\section{oxigénio}

Oxidase de citocromo C

Peroxidase di-hémica

\section{Enzimas do ciclo do azoto e enxofre}

Citocromo $\mathrm{cd}_{1}$ (Redutase de nitrito).

Redutase de sulfito
Nitrogenase
Urease

Produção e consumo de hidrogénio

Hidrogenase [NiFe]

Hidrogenase [Fe]

\section{Conversão ADN-ARN}

Redutase do ribonucleotídeo

\section{Mo e W em Biologia}

Oxido-redutase de aldeído (Mo, W)

Redutase de DMSO (Mo)

Desidrogenase de formato (W)

Oxidase de sulfito $(\mathrm{Mo})$

Desidrogenase de $\mathrm{CO}(\mathrm{Mo})$

As estruturas das metaloproteínas publicadas revelam grande variedade de soluções estruturais e permitiram a visualização de centros catalíticos chave em processos bioquímicos primordiais. Uma vez determinada a estrutura, uma nova fase se inicia: o estudo e observação detalhada dos ligandos, das geometrias e da vizinhança do centro catalítico vão ser determinantes nos aspectos mecanísticos. ${ }^{2}$ 


\section{F - ESSENCIALIDADE E TOXICIDADE DOS ELEMENTOS QUÍMICOS}

\section{Elementos essenciais e tóxi-} $\cos$

Um elemento químico (ou qualquer outra substância) diz-se essencial se, quando fornecido em doses inferiores a um determinado valor, a sua carência afectar o desenvolvimento ou as funções metabólicas normais de um determinado organismo.

Um elemento químico diz-se tóxico se, quando fornecido a um organismo em doses superiores a um determinado valor, impede o desenvolvimento ou prejudica as funções metabólicas desse organismo.

Deve-se referir que todos os ele- mentos químicos são tóxicos quando em concentrações muito elevadas, incluindo os elementos ditos essenciais.

\section{Armazenamento e distribui-} ção dos elementos químicos Efeitos da deficiência e excesso de elementos essenciais - Relação causa/efeito.

Os elementos essenciais são armazenados, o que implica acumulação ou seja manutenção de uma concentração elevada desse elemento num dado local, ou seja dispêndio de energia ligado a um processo de transporte activo. A acumulação pressupõe fixação de um elemento, envolvendo ligandos biológicos selectivos em relação a esse elemento. No caso de haver armazenagem, os requisitos diários são apenas os necessários para manter os níveis depositados.

Processos de armazenagem e disponibilização de elementos químicos têm sido descritos e detalhadamente estudados. O caso do ferro em biologia é paradigmático. O mesmo se pode dizer para o percurso biológico de cálcio e zinco.

Deficiência e excesso de certos elementos químicos (relacionar com efeito de essencialidade e toxicidade) manifestam-se na forma de doenças ou perturbações fisiológicas. Apenas alguns exemplos são referidos na Tabela 11 .

Tabela 11 - Elementos químicos / efeitos, perturbações

\begin{tabular}{|c|c|c|}
\hline Elemento químico & Manifestações & Efeitos \\
\hline Cálcio & $\begin{array}{l}\text { Enfraquecimento dos ossos } \\
\text { Excitabilidade neuromuscular } \\
\text { Tetania }\end{array}$ & $\begin{array}{l}\text { Espessamento dos ossos e } \\
\text { Calcificação de cartilagens } \\
\text { Cálculos urinários } \\
\text { Paragens cardíacas }\end{array}$ \\
\hline Cobre & $\begin{array}{l}\text { Anemia } \\
\text { Ataxia em carneiros } \\
\text { Queratinização deficiente } \\
\text { Pigmentação deficiente }\end{array}$ & $\begin{array}{l}\text { Doença de Wilson } \\
\text { Necrose hepática } \\
\text { Cirrose } \\
\text { Crises homolíticas }\end{array}$ \\
\hline Flúor & $\begin{array}{l}\text { Cárie dentária } \\
\text { Mortalidade perinatal }\end{array}$ & Fluorose \\
\hline Ferro & Anemia & $\begin{array}{l}\text { Hemocromatose } \\
\text { Hemosiderose } \\
\text { Hemorregias } \\
\text { Falhas cardíacas }\end{array}$ \\
\hline lodo & $\begin{array}{l}\text { Bócio } \\
\text { Deficiências reprodutoras } \\
\text { Queda de cabelo }\end{array}$ & Bócio \\
\hline Selénio & $\begin{array}{l}\text { Necrose hepática } \\
\text { Distrofia muscular } \\
\text { Esterilidade } \\
\text { Lesões de tecidos } \\
\text { Artrite crónica }\end{array}$ & $\begin{array}{l}\text { Cambaleio cego } \\
\text { Doença alcalina (gado) }\end{array}$ \\
\hline Silício & $\begin{array}{l}\text { Deformações ósseas } \\
\text { Defeitos nas cartilagens } \\
\text { Maior incidência e doenças cardiovasculares }\end{array}$ & Silicose \\
\hline Zinco & $\begin{array}{l}\text { Anorexia } \\
\text { Raquitismo } \\
\text { Hipogonadismo } \\
\text { Dificuldades de cicratização }\end{array}$ & $\begin{array}{l}\text { Febre de fumos metálicos } \\
\text { (febre, tremores) }\end{array}$ \\
\hline
\end{tabular}




\section{Elementos químicos e medi- cina /farmacologia}

O campo de interacção entre química bio-inorgânica e medicina / farmacologia é um tema de grande actualidade e que pode ser explorado. O conhecimento dos mecanismos pelos quais estes elementos (pela sua presença em excesso ou defeito) afectam os sistemas biológicos é de grande interesse. A toxicidade dos elementos químicos pode ser causado por vários efeitos:

i) ligação de metais pesados a enzimas, podendo interferir com grupos ou centros activos. Mercúrio e chumbo podem substituir ferro em centros catalíticos contendo enxofre ou ligar-se a grupos - $\mathrm{SH}$ funcionais (ver Apêndice C)

ii) interferência com moléculas biológicas importantes para a função de enzimas (efeito de complexação)

iii) iões como arsenato, tungstato, selenato, telurato podem interferir na utilização de sulfato e fosfato (analogia estrutural)

iv) precipitação de elementos essenciais (ex. caso de formação de sulfuretos metálicos insolúveis)

v) interferências a nível da permeabilidade das membranas biológicas (ex. caso de radicais que promovem a peroxidação de lípidos) e alteração de mecanismos de transporte de iões (ex. acção de $\mathrm{Li}^{+}$no transporte de $\left.\mathrm{Na}^{+}\right)$.

\section{Contaminação e poluição}

Contaminação é o resultado de uma descarga, em concentrações superiores ao normal de elementos, compostos ou outras substâncias; quando esta situação tem um efeito tóxico potencial para os seres vivos estamos numa situação de poluição.

A poluição pode afectar a atmosfera, águas e solos. Muitos dos conceitos descritos ajudam a uma compreensão do fenómeno e propor remediação efectiva a estes problemas, que pode passar não só por tratamentos químicos mas também por acção de agentes biológicos. É no entanto um problema complexo que exige um consórcio de activida- des complementares, requerendo um conhecimento básico adequado de disciplinas como Química Analítica e Inorgânica, Bioquímica, Biologia

\section{G - CICLOS DOS ELEMENTOS}

A troca de elementos químicos entre a bio e a geosfera é um processo que decorre correntemente perante os nossos olhos. Os elementos químicos são utilizados em contínuo e reciclados e portanto a sua utilização pode ser optimizada. O dióxido de carbono, o carvão, o calcário, o petróleo, o azoto e os nitratos são exemplos de elementos e compostos em transformação contínua de matéria. Os seres vivos têm um papel importante no estabelecimento dos ciclos dos elementos, seu equilíbrio e manutenção. Os ciclos do $\mathbf{O}, \mathbf{S}, \mathbf{N}$ e $\mathbf{C}$ são exemplos que demonstram bem estes conceitos. Mais ainda: em muitos casos, os ciclos dos elementos podem ser alternativos e complementares. O mesmo organismo pode utilizar vias alternativas. Bactérias que reduzem sulfato podem sobreviver em meios aquáticos naturais contendo nitrato. Neste caso, o resultado da adaptação ao ecossistema leva à indução de enzimas que podem utilizar nitrato. Estabelece-se uma inter-relação entre os ciclos de utilização de enxofre e de azoto.

A reciclagem dos elementos químicos permite a sua incorporação em biomoléculas essenciais (ASSIMILAÇÃO) mas os mesmos elementos podem ser usados em processos que permitem retirar, disponibilizar e armazenar energia (DISSIMILAÇÃO). A respiração de oxigénio é um exemplo típico deste processo. No entanto a respiração pode ser considerada num sentido lato, e muitos processos redutivos ocorrem que têm uma função idêntica à utilização do oxigénio. Etapas multi-electrónicas ocorrem que representam processos primordiais nos ciclos dos elementos:

$$
\begin{aligned}
& \mathrm{O}_{2} \rightarrow \mathrm{H}_{2} \mathrm{O} \\
& \mathrm{NO}_{3}^{-} \rightarrow \mathrm{NO}_{4}^{-} \rightarrow \mathrm{NO} \rightarrow \mathrm{N}_{2} \mathrm{O} \rightarrow \mathrm{N}_{2} \\
& \left(\mathrm{Ou} \mathrm{NO}_{2}^{-} \rightarrow \mathrm{NH}_{4}^{+}\right) \\
& \mathrm{SO}_{4}^{2^{-}} \rightarrow \mathrm{SO}_{3}^{2^{-}} \rightarrow \mathrm{S}_{2}^{-} \\
& 2 \mathrm{H}^{+} \rightarrow \mathrm{H}_{2} \\
& \mathrm{CO}_{2}+\mathrm{H}_{2} \rightarrow \mathrm{CH}_{4}
\end{aligned}
$$

Muitas destas etapas ocorrem naturalmente devido à actuação de consórcios bacterianos. Por exemplo, a degradação de biomassa conducente à produção de metano pode ser considerada como uma cascata de reacções sucessivas que levam a decomposição de moléculas complexas, por exemplo celulose, até à sua transformação em moléculas simples como hidrogénio e metano (e dióxido de carbono).

O ciclo do azoto é um caso exemplar para o desenvolvimento destes conceitos (assim como o do enxofre). A possibilidade de utilização de azoto atmosférico é um factor do desenvolvimento de seres vivos que não o podem assimilar directamente. A importância do uso de fertilizantes azotados na agricultura é bem conhecido. A produtividade agrícola depende da disponibilidade de fontes de azoto num estado químico que possa ser assimilado pelas plantas. O azoto pode ocorrer em combinações e compostos variados que representam diferentes estados de oxidação deste elemento. Compostos em que o azoto é incorporado por uma via assimilativa são correntes nos seres vivos. Os amino-ácidos são exemplos bem conhecidos. A transformação e incorporação de azoto pelos seres vivos é um processo cíclico. Um ciclo complexo ocorre na transformação de compostos de azoto. Estas vias biológicas que alteram o estado de oxidação do azoto conduzem à fixação, assimilação, oxidação e redução de compostos tais como nitrato, nitrito, amónia e óxidos de azoto vários. A disponibilização de azoto numa forma facilmente assimilável, através do processo de fixação é um dos processos biológicos mais fascinantes e primordiais. Os fertilizantes são fontes de azoto e de outros elementos para a 
plantas. O processo industrial de produção de amónia requer temperaturas e pressões elevadas, assim como a utilização de catalizadores químicos. Assim o processo é dispendioso.

$\mathrm{Na}$ natureza a fixação de azoto é levada a cabo por um grupo de micro-organismos que têm a capacidade de fixar o azoto atmosférico a temperaturas e pressões ambientes. O azoto assim fixado (transformado em amónia) pode ser facilmente assimilado pelas plantas e transferidos para os outros seres vivos. Esta associação é bem reconhecida na natureza. Muitas vezes o azoto incorporado em culturas de leguminosa é reutilizado, através da incorporação do material vegetal no terreno, permitindo que novas culturas sejam realizadas com elevada produtividade.

O catalizador biológico que per-

\section{OUTROS CONCEITOS \\ Breves considerações \\ sobre a evolução da vida \\ Do simples para o complexo - da desordem à ordem}

A evolução "química" dos acontecimentos que ocorreram no planeta (e dos sistemas vivos em geral) é de grande interesse, em particular todos os processos que conduziram ao aparecimento da primeira célula viva (origem da viva e consequente evolução das espécies).

O leitor mais interessado deve consultar textos básicos que discutam estes tópicos em particular as Teorias de Darwin, Oparin e as experiência de Miller, que tentam reproduzir, por simulação, condições de uma atmosfera primitiva e assim demonstrar a possibilidade de sintetizar moléculas simples (precursoras de outras mais complexas). Deste modo tem sido proposto uma "genealogia" possível de moléculas simples para situações complexas que conduziriam após organização (meio interior versus exterior) à formação de organelos, células, tecidos, órgãos, organismos diferenciados, animais, etc. mite assimilação do azoto em condições ambientais é a nitrogenase. Esta enzima tem um papel fundamental na utilização de azoto por plantas, factor condicionante da produtividade agrícola. A enzima realiza esta reacção em condições suaves, $25^{\circ} \mathrm{C}$ e 1 atmosfera. O centro catalítico contem ferro, enxofre e molibdénio associados num agregado metálico. $\mathrm{O}$ molibdénio coordena ainda uma molécula orgânica - isocitrato. Esta é ainda hoje uma das reacções químicas mais intrigantes levadas a cabo pelos sistemas biológico. Além da amónia, nitratos e nitritos são utilizados em indústrias química, alimentar e agrícola.

Uma enzima relevante na transformação de nitrato é a redutase de nitrato que pode transformar por via redutiva nitrato em nitrito. Esta enzima é uma metalo-proteína que

\section{TÓPICOS E CONCEITOS A RETER (Ao modo de um breve Glossário) \\ Os elementos da química
da vida}

Identificar os elementos químicos seleccionados pelos seres vivos. Sugerir uma consulta da Tabela Periódica dos Elementos. Estabelecer a noção de que os elementos mais leves são os mais utilizados. Os elementos da química da vida podem ainda ser classificados em três grandes grupos: os mais abundantes, os menos abundantes e os vestigiários (menor quantidade não significa menor importância como se verá adiante). Relacionar com a "Selecção dos elementos químicos por sistemas biológicos" e "Essencialidade e toxicidade dos elementos". Importante é também o conceito de resposta dos seres vivos a condições ambientais diversas e formas químicas estáveis desses elementos nessas condições.

\section{Tópicos:}

Identificação dos elementos químicos constituintes dos seres vivos

Elementos mais abundantes

Elementos menos abundantes contem molibdénio no centro catalítico e outros centros (centros ferroenxofre e / ou hemos). A sua acção catalítica leva à acumulação de nitrito. O nitrito acumulado pode em seguida ser transformado pela acção sequencial de outra enzima, a redutase de nitrito. Existem diferentes vias para esta transformação. Certas enzimas podem transformar nitrito directamente em amónia (enzimas hémicas). Outras reduzem nitrito a monóxido e azoto. Estas enzimas contêm cobre no centro activo.

Uma utilização e acumulação excessivas de nitratos e nitritos pode ter efeitos prejudiciais para o ambiente. Nitrato (e nitrito) podem no entanto ser transformados e reutilizados. Os sistemas biológicos têm portanto um papel importante na despoluição e tratamento de efluentes.

\section{Elementos vestigiários \\ Elementos supostos (não provados) essenciais}

Conceito de meio interior e exterior - Condições ambientais limitantes à química da vida

\section{Selecção dos elementos químicos por seres vivos}

Após identificação dos elementos químicos utilizados pelos sistemas biológicos, discutir os critérios que conduzem à selecção desses elementos, isto é, uma gestão económica de recursos. O aluno ao estabelecer critérios de selecção deduz imediatamente que um elemento abundante deve ser o mais utilizado. No entanto, compreenderá que este é um dos critérios (mas não único). Para um estudo mais aprofundado deve familiarizar-se com as espécies que são estáveis em solução aquosa (uma leitura do Apêndice A pode ajudar numa discussão de como o solvente aquoso limita as propriedades ácido-base e de oxidaçãoredução). Introduzir assim o critério de disponibilidade de um elemento químico e de versatilidade química.

Tópicos:

Selecção de elementos químicos 

naturais

Utilização económica de recursos

Abundância e disponibilidade mentos

Espécies químicas estáveis dos ele-

Luta contra a adversidade

Captura e concentração de elementos químicos raros

Mecanismos de captura - competição

Funções dos elementos químicos

Identificar as principais funções desempenhadas pelos sistemas biológico. O papel dos elementos químicos é dividido em: funções electroquímicas (relacionadas com o envolvimento de iões em controle de carga e força iónica, com implicações também em transmissão de informação): funções estruturais (como constituintes de moléculas envolvidas na construção da estrutura viva: um exemplo a reter é o da estrutura óssea) e funções catalíticas (as enzimas tem um papel muito importante em permitirem a ocorrência de reacções químicas em condições de pressão e temperatura normais - introdução do conceito de reaç̧ão catalizada). Os metais têm, neste aspecto de catálise, um papel fundamental. Definir o grupo das metalo-enzimas que apresentam uma elevada especificidade e tem uma intervenção como catalisadores de reaç̧ões ácido-base e de oxidação-redução

\section{Tópicos:}

Identificação das funções desempenhadas pelos elementos químicos

Classificação funcional dos elemen- tos essenciais

Funçôes electroquímicas, estruturais, catalíticas e outras

Enzimas activadas por metais: Metalo-enzimas

\section{Enzimas e elementos metálicos}

Introduzir da noção de relação íntima entre metal e proteína. As metalo-proteínas, assim constituídas, têm um papel fulcral na catálise de reacções biológicas (metalo-enzimas). Algumas noções mecanísticas devem ser introduzidas. Apresentação de exemplos representativos deste grupo de catalisadores biológicos e conceitos tais como cofactor, coenzima, grupo prostético e inibidor. Muitos conceitos básicos da Química Inorgânica podem ser relembrados e utilizados para compreender a geometria afinidade dos ligandos em torno dos metais que constituem os centros activos destas metaloproteínas. De notar o papel importante das cadeias laterais de aminoácidos como grupos coordenantes de metais. $\mathrm{O}$ aluno deve também reconhecer geometrias típicas de coordenação envolvendo ferro, zinco e cobre.

\section{Tópicos:}

Proteínas globulares versus catálise enzimática

Catalisadores biológicos

Perfis de energia de activação (reacções catalisadas e não catalisadas)

Enzimas activadas por metais

Metalo-enzimas - Estruturas de centros activos - Geometrias e ligandos

Mecanismos enzimáticos

\section{Essencialidade e toxicidade dos elementos químicos}

A utilização de elementos químicos por sistemas biológicos tem sempre um carácter de dualidade: por um lado os elementos são essenciais para o desempenho de determinadas funções biológicas mas quando presentes em concentrações podem ser tóxicos. Por outro lado certos elementos químicos nunca manifestam um carácter de essencialidade e são extremamente tóxicos (caso do mercúrio). Neste contexto o aluno deve reconhecer os conceitos de essencialidade e toxicidade (ou, por outras palavras, efeitos benéficos e prejudiciais dos elementos). A afinidade dos elementos metálicos para sistemas biológicos (e, por exemplo, o carácter tóxico) pode ser discutido em termos químicos (ver Apêndice C). A forma da curva de variação do efeito biológico dos elementos essenciais descrita neste capítulo deve ser aprofundada.

O aluno deve ainda identificar situações de carência e efeito nocivo dos elementos químicos em sistemas biológicos.

\section{Tópicos:}

Elementos tóxicos

Armazenamento e distribuição dos elementos químicos

Efeitos da deficiência e excesso de elementos essenciais

Relação causalefeito

Contaminação e poluição

\section{OUTROS ASSUNTOS \\ RELACIONADOS \\ (não detalhados neste texto)}

\section{Principais moléculas biológicas: características e funções}

Noções básicas sobre as quatro principais macromoléculas utilizadas pelos seres vivos: proteínas, polissacáridos, lípidos e ácidos nucleicos. Importante é o reconhecimento das unidades constitutivas e do tipo de ligação que se estabelece entre as unidades constituintes.
Um dos aspectos mais importantes a reter é que as macromoléculas biológicas são polímeros de unidades bem definidas. Estes monómeros, com uma estrutura básica precisa, são utilizados como blocos construtores. Pequenas variações estruturais são introduzidas de modo a conferir versatilidade estrutural. Um bom exemplo a aprofundar é o caso das proteínas construídas a partir de 20 amino-ácidos, em que a grupo $\mathrm{R}$ substituinte introduz propriedades específicas às unidades constituintes. É interessante este conceito de utili- zação de uma unidade básica que é repetida com pequenas variações estruturais (novamente a ideia de economia de recursos numa via metabólica). O exemplo das proteínas deve também servir para ilustrar conceitos de organização estrutural a vários níveis. Estas ideias podem também ser exploradas nos outros grupos de macromoléculas. A membrana biológica deve ser apresentada permitindo discutir não só sobre o carácter anfipático dos lípidos mas também a de organização celular das macromoléculas. 
Tabela 12 - Principais moléculas biológicas e suas unidades constituintes

\begin{tabular}{lll}
\hline macromoléculas & Unidades constitutivas & Ligação química \\
\hline proteínas & Amino-ácidos & peptídica \\
polissacáridos & Monossacáridos & glicosídica \\
lípidos & ácidos gordos e outras moléculas & Novalente" sem nome particular \\
ácidos nucleicos & Nucleótidos & \\
(base-monossacárido-fosfato) & Monossacárido - fosfato & \\
\hline
\end{tabular}

\section{Tópicos:}

Macromoléculas de interesse biológico Proteínas, Polissacáridos, Lípidos e Ácidos nucleicos

Unidades constituintes nómeros

Tipo de ligação ocorrente entre mo-

Noções elementares sobre ofuncionamento da célula viva

\section{APÊNDICES}

\section{APÊNDICE A}

\section{- A água como solvente}

Produto iónico da água - Conceito de $\mathrm{pH}$

Em solução aquosa ocorre o equilíbrio de auto dissociação do solvente:

$$
2 \mathrm{H}_{2} \mathrm{O} \leftrightarrow \mathrm{H}_{3} \mathrm{O}^{+}+\mathrm{OH}^{-}
$$

A constante de equilíbrio desta reacção é descrita como:

$$
\mathrm{K}=\left(\mathrm{H}_{3} \mathrm{O}^{+}\right)\left(\mathrm{OH}^{-}\right) /\left(\mathrm{H}_{2} \mathrm{O}\right) \text {. }
$$

Esta constante designada por $\mathrm{K}_{\mathrm{w}}$ - PRODUTO IÓNICO da água tem um valor a $25^{\circ} \mathrm{C}$ de cerca de $10^{-14}$. Logo, as concentrações de $\mathrm{H}_{3} \mathrm{O}^{+} \mathrm{e}$ $\mathrm{OH}^{-}$estão relacionadas. $\mathrm{O}$ conceito de $\mathrm{pH}=-\log \left(\mathrm{H}_{3} \mathrm{O}^{+}\right)$indica que $\mathrm{pH}+$ $\mathrm{pOH}=14$.

\section{Comportamento redox da água}

A água também pode tomar parte em reacções de oxidação-redução, quer actuando como redutor quer como oxidante.

\section{Funcionamento esquemático} da célula viva e breves considerações sobre a evolução da vida

Descritas as moléculas biológicas relevantes, discutir um esquema simplificado de funcionamento de uma célula viva. As matérias primas são obtidas da energia solar ou da energia do metabolismo (por exemplo, respiração ou fermentação). Todos os conceitos podem motivar trões)

Como oxidante (captando elec-

$2 \mathrm{H}_{2} \mathrm{O}+2 \mathrm{e} \rightarrow \mathrm{H}_{2}+2 \mathrm{OH}^{-}$

Logo $\mathrm{E}=\mathrm{E}_{\mathrm{O}}+0,059 / 2 * \log$ $\left[\left(\mathrm{H}_{3} \mathrm{O}^{+}\right) /\left(\mathrm{H}_{2}\right)\right]=0-0,06 \mathrm{pH}(\mathbf{A}), \mathrm{a}$ $25{ }^{\circ} \mathrm{C}$ e à pressão de $1 \mathrm{~atm}$.

Como redutor (dador de electrões)

$2 \mathrm{H}_{2} \mathrm{O} \rightarrow \mathrm{O}_{2}+4 \mathrm{H}^{+}+4 \mathrm{e}$

$\mathrm{E}=1,23-0,06 \mathrm{pH}(\mathbf{B})$

Ambas as reacções de oxidação-redução, definidas pelas equações A e B, são dependentes do valor de $\mathrm{pH}$ do meio. As espécies estáveis em solução aquosa devem ter valores de potencial de oxidação-redução compreendido entre estas duas linhas paralelas, que delimitam a zona de estabilidade do solvente.

\section{APÊNDICE B \\ - Competição de metais para um ligando}

Os sistemas biológicos enfrentam o problema de selecção e captação de elementos metálicos a partir do meio exterior. Consideremos um uma discussão alargada e integrada sobre a evolução da vida, i.e, o conceito do caminhar do simples para o complexo, e a possibilidades de usar compostos químicos simples como blocos construtores de estruturas mais complexas.

\section{Tópicos:}

matérias primas

energia

manual de instruções (ADN). exemplo muito simplificado de dois metais $M_{1}$ e $M_{2}$ em competição para um mesmo ligando L (que representa aqui uma proteína ou um receptor, por exemplo).

As constantes de estabilidade são definidas para os equilíbrios:

$\mathrm{M}_{1}+\mathrm{L} \leftrightarrow \mathrm{M}_{1} \mathrm{~L}$ e $\mathrm{M}_{2}+\mathrm{L} \leftrightarrow \mathrm{M}_{2} \mathrm{~L}$

Consideremos que o ligando não forma espécies protonadas (ou que as condições experimentais são tais que o valor de $\mathrm{pH}$ permite considerar estas espécies desprezáveis).

Se $K_{M_{1} L}>K_{M_{2} L}$ o metal $M_{1}$ é preferido pelo ligando $\mathrm{L}$.

Do ponto de vista quantitativo, para que a ligação de um metal a um ligando seja efectiva $\mathrm{K}>10^{7}$.

Todo o ligando não utilizado pelo metal $\mathrm{M}_{1}$, designado por [L] pode ser balanceado pela equação simples:

$$
\begin{aligned}
& {[\mathrm{L}]^{\prime}=[\mathrm{L}]_{\text {livre }}+\left[\mathrm{M}_{2} \mathrm{~L}\right]=} \\
& =[\mathrm{L}]\left(1+\mathrm{K}_{\mathrm{M}_{2} \mathrm{~L}}\left[\mathrm{M}_{2}\right]\right)=[\mathrm{L}] \alpha_{\cdot} \\
& \alpha_{\mathrm{L}} \text { é um termo correctivo que }
\end{aligned}
$$
tem em conta que o ligando L participa numa reacção de competição com o metal $\mathrm{M}_{2}$.

Como em geral, 
$\mathrm{K}_{\mathrm{M}_{2} \mathrm{~L}}[\mathrm{~L}] \gg>1, \log \alpha_{\mathrm{L}}=\mathrm{K}_{\mathrm{M}_{2} \mathrm{~L}}\left[\mathrm{M}_{2}\right]$, $\mathrm{K}_{\mathrm{M}_{1} \mathrm{~L}}^{\prime}=\left[\mathrm{M}_{1} \mathrm{~L}\right] /\left[\mathrm{M}_{1}\right][\mathrm{L}]^{\prime}=$ $=\left[\mathrm{M}_{1} \mathrm{~L}\right] /\left[\mathrm{M}_{1}\right][\mathrm{L}] \mathrm{K}_{\mathrm{M}_{2} \mathrm{~L}}\left[\mathrm{M}_{2} \mathrm{~L}\right]=$ $=\mathrm{K}_{\mathrm{M}_{1} \mathrm{~L}} /\left(\mathrm{K}_{\mathrm{M}_{2} \mathrm{~L}}\left[\mathrm{M}_{2}\right]\right)$

[L]' significa a concentração de L não ligada ao metal $\mathrm{M}_{1}$.

$\mathrm{K}_{\mathrm{M}_{1} \mathrm{~L}}^{\prime}>10^{7}$, portanto $\Delta \log \mathrm{K}+$ $+\mathrm{pM}_{2}>10^{7}$.

$\mathrm{K}_{\mathrm{M}_{1} \mathrm{~L}}$ é a constante de estabilidade de $M_{1}$ com $L$, que reflecte o facto de existir um equilíbrio secundário com $\mathrm{M}_{2}$. Se o metal interferente tiver uma concentração da ordem de $10^{-3} \mathrm{M}$, a captura de $\mathrm{M}_{1}$ só é selectiva se as constantes de estabilidade de $\mathrm{L}$ com $\mathrm{M}_{1}$ e $\mathrm{M}_{2}$ diferirem de mais de 4 ordens de grandeza.

\section{APÊNDICE C}

\section{- Classificação dos iões metálicos} (Ahrland, Chatt and Davies)

A classificação dos metais e suas propriedades, nomeadamente a sua apetência para certos ligandos è em parte um reflexo da sua estrutura electrónica, contendo camadas preenchidas e semi-preenchidas. Em particular a existência de camadas semi-preenchidas confere aos metais uma capacidade de variabilidade de estado de oxidação.
Uma divisão possível dos metais em duas classes de iões aceitadores de ligandos [classe a) e b)] foi apresentada por aqueles autores. Esta classificação é baseada no facto de que estas duas classes têm diferentes afinidades para os ligandos em solução.

A classe a) forma complexos mais estáveis com azoto, oxigénio e flúor (Grupos V, VI e VII). A maior parte dos metais estão aqui incluídos. Exemplos são os metais alcalinos e alcalino-terrosos, zinco e alguns metais de transição (até ao Grupo VI).

Em solução aquosa, a ordem de estabilidade dos aceitadores de classe a) com halogéneos varia na ordem $\mathrm{F}>\mathrm{Cl}>\mathrm{Br}>\mathrm{I}$ de acordo com a electronegatividade dos ligandos.

Os aceitadores de classe b) formam espécies complexas mais estáveis com fósforo, enxofre, cloro e com os elementos mais pesados. Inclui cádmio, mercúrio e outros elementos pesados tais como tálio, chumbo e bismuto.

A ordem de afinidade anterior inverte-se: $\mathrm{F} \ll<\mathrm{Cl}<\mathrm{Br}<\mathrm{I}$.

Assim a classe a) é definida por complexos em que a ligação forma- da tem um carácter predominantemente electrostático. Os elementos da classe b) tem um carácter covalente. Camadas semi-preenchidas podem modular o tipo de coordenação entre a classe a) e b) dependendo do maior ou menor número de electrões. Um caso típico são os metais de transição. Assim um aumento de estado de oxidação (perda de electrões) pode mudar as características de classe b) em a).

\section{AGRADECIMENTOS}

Ao M. Palma e P. Tavares por contribuições várias.

* Departamento de Quimica e Centro de Química Fina e Biotecnologia

Faculdade de Ciências e Tecnologia.

Universidade Nova de Lisboa 2925-114 Monte de Caparica, Portugal Tel. 2948345, fax 2948550 email jose.moura@da.fat.uml.pt http//www.dq.fct.uml.pt

NOTAS

1 A estabilização de um dado estado de oxidação de um metal por ligandos biológicos pode ser facilmente discutida com base em conceitos de Quimica Analítica: efeito de reacções de coordenação no potencial de oxidação-redução.

2 I. J. G. Moura, Boletim da SPQ 63(1996), 35-42.

Tabela 13 - Divisão dos metais em duas classes de iões aceitadores de ligandos

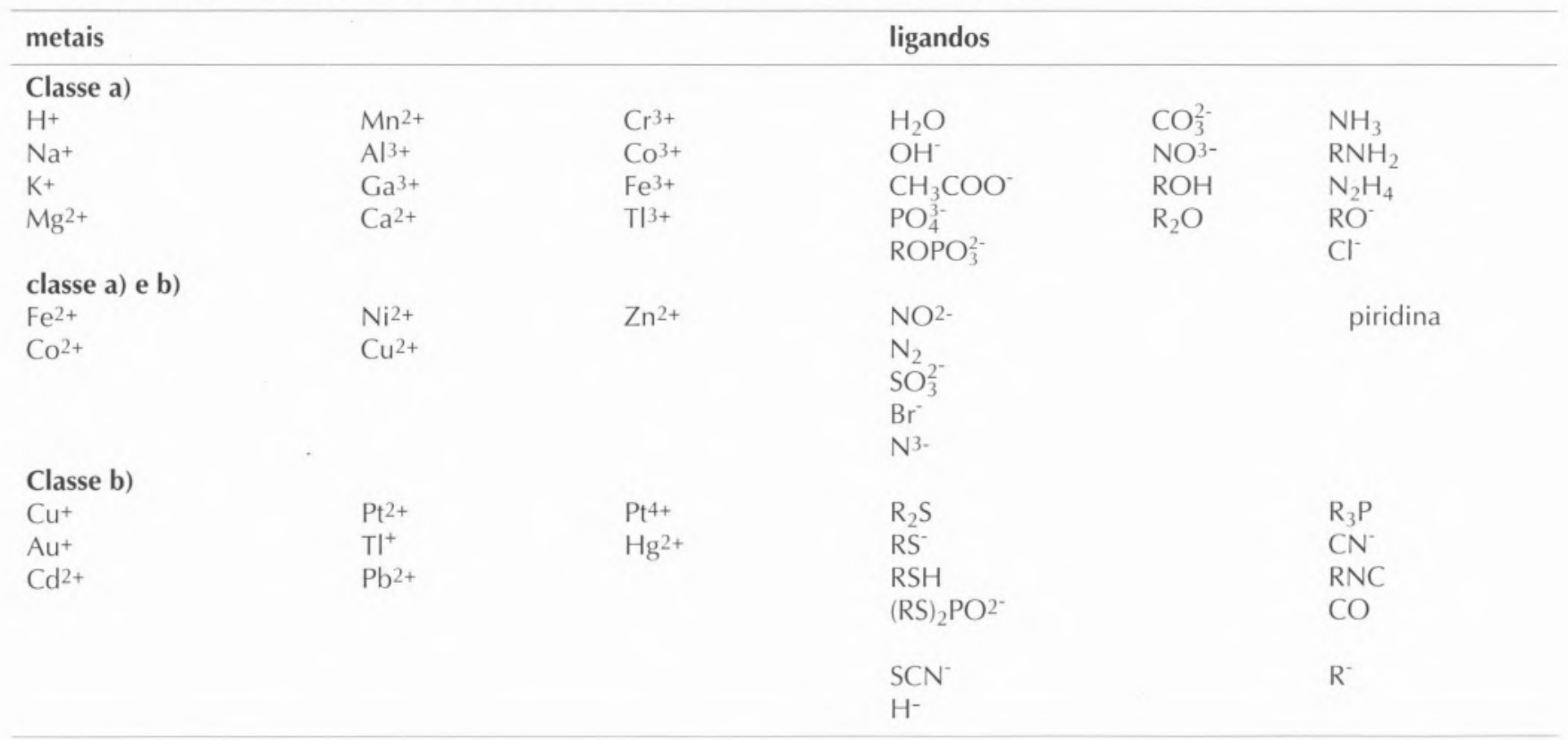




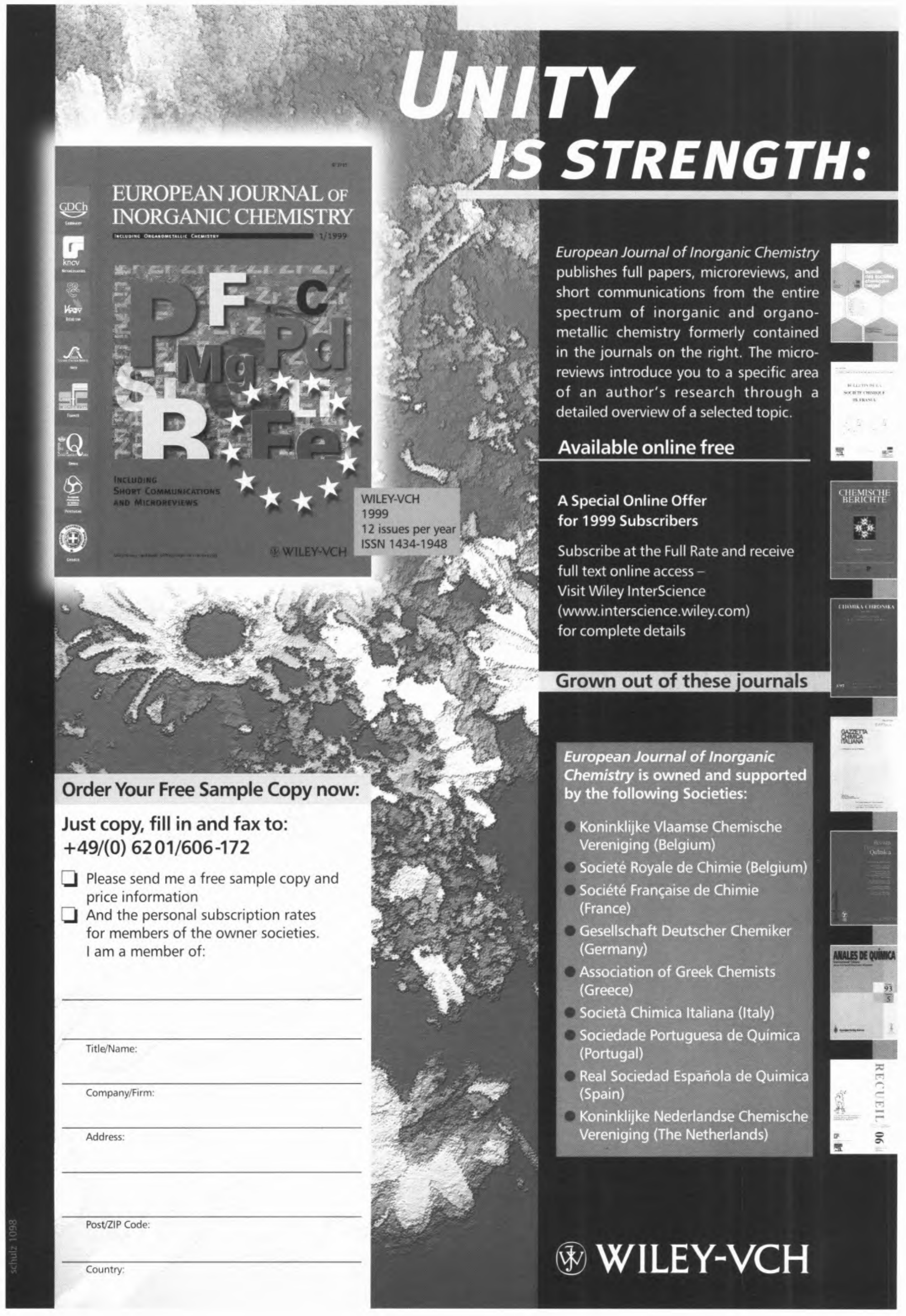

